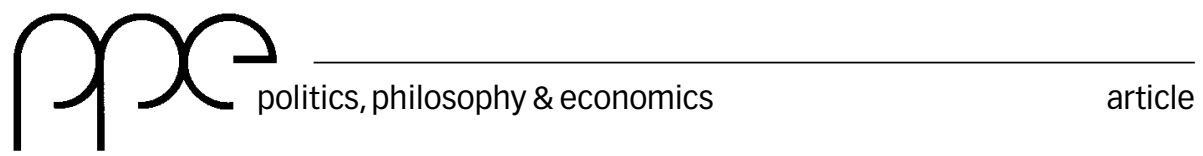

(c) SAGE Publications Ltd

London

Thousand Oaks, CA

and New Delhi

1470-594X

$2006105(3)$ 363-376

\title{
Voluntary losses and wage compensation
}

\author{
Simon Wigley \\ Bilkent University, Turkey
}

abstract This article endeavors to establish the moral force behind the worker's claim to a compensatory wage in return for the labor burdens she endures. The apparent incompatibility between compensation and voluntary losses suggests that the only reason for providing a compensatory wage is the need to entice a valued service. In response, the article considers and rejects attempts to ground the compensatory wage on duress, mutual trade, and desert. Instead, it argues that the worker is not responsible for her loss of well-being because she would not have incurred it in the absence of the employer's promise to compensate.

keywords compensatory wage, contributory wage, detrimental reliance, desert, labor burdens, promises, responsibility

\section{Introduction}

Most would readily accept that those that work in more stressful, tedious, and unpleasant jobs should be paid extra in order to make good the personal wellbeing they have forgone. But why, we may ask, should a person be compensated for a loss that is brought about by a job that she consents to perform? The fact that she could have chosen not to work, or to find a job that is more closely aligned with her personal preferences, appears to nullify her claim to have her loss remedied by the employer. Thus, with the exception of forced labor, slavery, and an accident in the workplace, labor burdens appear to be a clear-cut example of where the claimant is not an innocent victim. By the same token, it seems that the employer cannot be construed as a wrongdoer and so it is not clear why he should be obliged to compensate the worker's loss. In order to clarify further the 
nature of the problem posed by voluntary labor burdens, consider what I take to be three standard attempts to explain it away.

\section{Duress}

Broadly speaking, there are two independent determinants of a worker's wage: the wage she receives in return for the value generated by her performances (henceforward, contributory wage) and the wage she receives in order to make good the loss of well-being (for example, net preference denial) that she incurs during the course of those performances (henceforward, compensatory wage). The total wage is the summation of the contributory and compensatory wages. The argument from duress contends that workers are not responsible for the loss they incur to the extent that they would not be able to lead a sufficiently decent life in the absence of the contributory wage. Equally, the employer is obliged to compensate for any loss in the worker's well-being because otherwise he would be exploiting the latter's predicament. The problem with that line of argument is that it only has force if a worker does not have access to an eligible non-work alternative. In other words, a worker's claim to compensation appears to collapse when she is self-sufficient or has access to adequate state support. Thus, the argument from duress is consistent with some workers incurring an uncompensated loss of well-being. That suggests that we require a basis for compensation that is not contingent on whether the worker lacks access to a reasonable alternative.

\section{Incentive wage}

An alternative strategy is to argue that where making good the worker's loss is necessary in order to entice her to perform a valued service, it would be efficacious if we disregard the fact that the worker has voluntarily chosen to work. ${ }^{1}$ The problem that then arises is that, even if the worker is adequately compensated by that strictly incentive-based approach, the effect is to treat her as if her choices have no significance; that they have no bearing on how she is to be treated by others. ${ }^{2}$ The apparent incompatibility between wage compensation claims and personal responsibility poses a serious problem if we wish to remain sensitive to both the predicament of workers and voluntary choice at the same time. G.A. Cohen, for example, argues that labor burdens cannot be discounted from an adequate account of well-being, ${ }^{3}$ and yet compensatory treatment is only due to a person if the disadvantage he has incurred 'does not reflect choices that he has made or is making or would make'. ${ }^{4}$ In what follows, I shall endeavor to formulate an agent-centered basis for wage compensation that holds even though the worker is in a position to choose otherwise.

\section{Mutual trade}

One such possibility is to argue that the force behind the worker's claim to a compensatory wage derives from a mutually agreed trade between the worker and the 
employer of the following form: W agrees to carry out a performance requested by $\mathrm{E}$, and $\mathrm{E}$ agrees to compensate $\mathrm{W}$ for the loss she incurs as a result of that performance (as well as to provide a contributory wage in return for the value that arises because of that performance). According to that account, the agency of the worker is acknowledged because the exchange requires her acquiescence and the employer is obliged to make good the worker's loss simply because he has agreed to; thus, the question of who was responsible for the resulting loss has no bearing on why compensation is due. The first problem with this contractualist account is that it only requires that the employer compensate to the extent stipulated by the agreement, rather than for the loss that is actually incurred by the worker. ${ }^{5}$ Hence, the worker may be over- or under-compensated by the agreement if the extent of the well-being she forgoes turns out to be less or more than both parties expected. Now, as I indicate below (Section 4), there may be a good reason why the employer should keep to his word in such cases, even if that would mean over-compensating the worker. But because that reason pertains in spite of the actual incidence of harm, it does not provide us with the right reason as to why the worker should be compensated. That is, unless we are willing to countenance the idea of compensating where there is no harm and not compensating when there is harm, we require an account of why the employer should make good the worker's loss that does not simply stem from the obligation to keep one's word - a reason that is triggered by the actual incidence of harm. Second, we may question whether a person is bound to do something simply in virtue of the fact that at a previous moment in time he willed that obligation on himself. At least, if it can be shown that the worker's loss occurred because of the employer's agency, then the force behind his obligation to compensate will be considerably stronger than it would be if it turns out that it occurred because of factors beyond his control (that is, freely self-inflicted by the worker).

With that last suggestion in mind, I will argue here that the employer is obliged to make good the worker's loss not simply because he agreed to do so, but, more fundamentally, because the worker would not have incurred the loss if he had not done so. Accordingly, the employer is obliged to make good the loss incurred by the worker in relying on the agreement, rather than to the extent defined by the agreement. In addition, that compensation basis is agent centered in that it does not ignore the worker's choice to work. Finally, the moral force behind it is not contingent upon whether the worker was subject to duress when she chose to work.

The discussion that follows has only an indirect bearing on the contributory determinant of the worker's wage. However, it is worth noting from the outset that the compensatory determinant is invulnerable to the problem posed by the ubiquity of luck. A significant challenge to the worker's claim to a contributory wage is that her ability to acquire and perform well in a job is to a considerable extent dependent upon factors beyond her control, such as the genetic endowments she is born with, the social and economic conditions she is born into, the 
way she is raised, and so on, which conspire to help bring about something which is valued by others. In effect, the pervasive influence of luck severely undermines, even if it does not entirely nullify, the worker's ability to take credit for the value arising from her performance. It may be sufficient, therefore, to express our admiration of the worker's valued performance simply by praising her. By so doing, we adequately respect the agency of the worker without having to provide her with a material reward. Hence, if we take the problem of luck seriously, then it seems that the only reason we have for providing a wage over and above the compensatory wage is social efficiency: the use of unequal non-compensatory payments as a means to direct workers to those jobs in which they are most useful and to encourage them to work sufficiently hard once they are there. The compensatory wage avoids the problem posed by luck simply because it focuses on the loss incurred by the worker rather than on how much, if any, of the value generated by her performance she can take credit for. As we have seen, however, the moral force behind the worker's claim to a compensatory wage is undermined by the fact that her loss is freely self-imposed. Thus, while the worker's claim to a contributory wage is threatened by the absence of responsibility, her claim to a compensatory wage is threatened by the fact that she appears to be responsible for her loss. The latter problem is precisely what this article sets out to resolve.

I begin by examining the possibility that compensating voluntary losses is not contradictory because the reason for compensation lies in the very fact that the worker is responsible for the loss she incurs. Thus, in the following section (Section 2) I consider whether making good that loss can be construed as a fitting way for the employer to express his response to the worker's valued sacrifice or valued performance. I conclude that the employer's sentiments of gratitude or admiration are unable to establish the normative force behind the worker's compensation claim. Instead, I argue that the worker is not responsible for the labor burdens she incurs because she only agrees to endure them as a result of the employer's promise to compensate. Hence, while she may be responsible for her decision to work, it does not follow that she is responsible for the loss of well-being that results. As we shall see, the further implication of that line of argument is that the force behind the employer's obligation to compensate does not depend on his feeling of sympathy in response to the worker's innocent loss (see Section 3), but from the fact that he is responsible for it (see Section 4). I then endeavor to respond to three objections to the argument from detrimental reliance (see Section 5).

\section{Responsive attitudes}

I have already argued that the problem posed by voluntary labor burdens cannot be satisfactorily explained away by attempting to ground the compensatory determinant of the worker's wage on duress, incentive payments, or mutual trade. An alternative way around the apparent incompatibility between compensation 
and voluntariness emerges if we simply accept that she is fully responsible for the loss she incurs. According to that line of argument, self-imposed work harm entails the display of valued qualities and, therefore, should be taken as a reason for approval rather than as a reason to attribute personal fault. The question is what those valued qualities are and whether they require that compensation be the appropriate form of treatment.

\section{Gratitude}

One plausible candidate is the employer's feeling of gratitude in response to what the worker sacrifices on her behalf. That is to say, the employer owes a debt of gratitude to the worker for the harm she incurs in the course of creating value for him. Some might argue, however, that the employer's sense of gratitude is primarily directed toward the fact that the worker gives up the value created by her performance, rather than the fact that the worker forgoes personal well-being in the course of creating that value. But, whether the worker is actually alienating value, and therefore whether a debt of gratitude is owed, appears to hinge on the defensibility of the Lockean argument that we own ourselves, our abilities and actions, and, thereby, the fruits of our labor. Even if we accept the worker's ownership of the value her performance generates, that does not rule out the idea that the employer should be grateful for what the worker endures during the performance. Indeed, it seems consistent to argue that he should be grateful for a harmful performance that fails to generate value, even though it was intended to do so. Hence, the employer may express his gratitude to the worker by providing both a contributory wage in recognition of the value that she gives up and a compensatory wage in recognition of the well-being she forgoes in creating that value.

That does not get us very far, however, as gratitude would only seem to be an appropriate response if the worker was motivated by the desire to benefit the employer. ${ }^{6}$ Now I take it that the worker is typically only willing to endure harmful working conditions, first, because the expected compensatory wage will leave her no worse off and, second, because of the contributory wage she expects to receive. Hence, she is only concerned that the employer benefits to the extent that it ensures that she herself benefits overall. At the very least, any feeling of gratitude will be significantly weakened if the benefactor is only instrumentally concerned about the beneficiary's interests. Notice also that even when the worker is morally motivated the target of her beneficence is usually not the employer - for example, charity work or working so as to contribute to the resources available for redistribution in society. What these points suggest is that workers and employers can only be obligated to each other for reasons that hold irrespective of whether there is a sense of good will between them.

Even if we accept that gratitude is appropriate when the benefactor is not morally motivated, ${ }^{7}$ it remains indeterminate as to what constitutes the appropriate way of expressing it. Making up for the worker's loss appears to be only one 
way in which the employer may show his debt of gratitude. He may equally decide to show his appreciation by simply thanking his employees for their hard work. While gratitude pinpoints who is obligated and to whom, it does not require that compensation is the fitting response. Indeed, it seems quite plausible to have the feeling of gratefulness without actually reciprocating in any way. It is by no means clear, therefore, that gratitude imparts an obligation to repay the favor in some way.

\section{Admiration}

Closely allied to the responsive attitude of gratitude is the idea that the performance of a contributory self-sacrifice is something we admire. While both attitudes refer to the qualities inherent in the person's performance, admiration is not contingent upon whether the performance was morally motivated. We may admire the worker's willingness to make a sacrifice for another, but we can also simply admire the worker's courage in the face of adversity or his skill in handling adverse conditions. Hence the object of approval is the qualities exhibited by the performance, irrespective of whether the performer is only instrumentally concerned that others benefit from them.

Because it is not necessarily concerned with the quality of the worker's motivations, admiration may provide a superior way of grounding wage compensation. Indeed, if we interpret positive desert as the fitting response to the display of valued qualities, then admiration suggests a way in which wage compensation may constitute a deserved form of treatment. ${ }^{8}$ The plausibility of that enterprise, however, hinges on whether compensation can have the property of being deserved. Can it be construed as a fitting way of expressing our admiration of a performance? Our admiration of, say, a courageous performance can constitute a desert basis, but it is not clear that the right form of treatment in response to it is the making good of the worker's loss in acting courageously. Deserving responses such as praise, applause, reward, and so on add value to the recipient in return for the value they have added to the world. By contrast, compensation makes up for, rather than adds to, the worker's 'stock of value' and it is in response to the subtraction of value from the worker (that is, denial of wellbeing), rather than the addition of value to the world (that is, admired qualities). The upshot of this is that our admiration of the worker's courage in the face of adversity or her ability to handle adverse working conditions provides us with a way to ground her claim to an enlarged contributory wage and not her claim to a compensatory wage. ${ }^{9}$ Even if we persist, despite the conceptual awkwardness of doing so, with the idea that making good can be an appropriate response to the display of valued qualities, that merely leaves us, as in the case of gratitude, in a situation in which the appropriate response is indeterminate. 


\section{Innocent suffering}

Thus far, we have considered reasons for wage compensation that actually require that the worker is responsible for the labor burdens she endures. More specifically, I have examined whether the employer's response to the qualities displayed by the choice to endure harmful working conditions can provide a reason for compensatory treatment. I have argued that the moral and non-moral qualities that we might associate with the worker's self-imposed harm either do not pertain or do not require compensation as the fitting response. The basic problem is that, because our attitudes in response to those qualities do not refer to the worker's loss per se, making good that loss constitutes an ill-suited way of expressing those attitudes.

The upshot of this is that we should seek to base the worker's compensation claim on her innocent suffering rather than her control over the display of admired qualities. The question that then arises is how it can be that the worker is not responsible for her loss even though it was freely self-imposed.

The difficulty of distilling such an account is well illustrated by Joel Feinberg's seminal analysis of personal desert. ${ }^{10}$ There he argues that the employer has no special obligation to compensate because he did not commit a wrong. Nonetheless, the employer has a general obligation to provide succor or aid because workers are innocent sufferers; that is, he should compensate out of a sense of sympathy for the worker's undeserved harm. Hence, for Feinberg, balancing out a worker's denial appears to be akin to compensation in those cases, such as a natural disaster, in which no human agent is responsible. The only reason, he contends, that we have for compensating a person who is responsible for their predicament is out of a feeling of pity for their suffering. ${ }^{11}$

Notice that the reason for compensation that Feinberg provides is the claimant's negative desert (that is, no one who is innocent deserves to suffer or no one deserves to suffer), rather than the claimant's positive desert (that is, valued performance). Given the awkwardness of rewarding someone for what they are deprived of, I would agree that the appropriate starting point must be the worker's undeservedness. However, Feinberg's account fails to explain why, in spite of her consent, the worker's loss is undeserved and why, given that he is not responsible, it is the employer in particular who should be compensating, rather than just anybody who has the means to do so. ${ }^{12}$ The implication of his account, therefore, is that the only moral reason that the employer has for compensating his employees is if he, in particular, happens to pity them for their self-inflicted loss. A further problem here is that sympathy, or for that matter pity, does not specify the worker's loss as the required target of the benefactor's aid. I take it that what gives force to our feelings of sympathy and pity is the general obligation to alleviate suffering. But surely that obligation would recommend that the employer allocate his resources to those who are in the most urgent need, and it would be unusual if it was his employees that are suffering the most. Greater 
good may be achieved, for example, if the employer acquiesces in the taxation of those same resources in order to aid those who do not have a job and who are living in poverty.

\section{The argument from detrimental reliance}

What the preceding discussion indicates is that we require a compelling account of the sense in which the worker is not responsible for her loss (or at least not responsible in a way that would count against her compensation claim) and of the sense in which the employer is responsible for it (and, therefore, why he is specifically required to make good the worker's loss). With that in mind, I will argue that the worker's acquiescence would not have been given in the absence of the employer's compensatory promise and that the employer has a special obligation to compensate the worker because of the duty to avoid the infliction of harm. ${ }^{13}$

I contend that while the employer is not responsible for the harm in the sense that he forced the worker to incur it or brought it about through a lack of due care, he is responsible for it in the sense that without his promise of compensation it would not have been consented to in the first place. Crucially, it follows that the worker is not, in fact, responsible for the harm incurred because her consent (agreeing to perform or actually performing) is conditional upon that promise. While the worker does self-inflict the harm in the sense that she could have done otherwise, she only does so because of the expectation of being compensated.

This line of argument is analogous to the defense of entrapment against a criminal charge: in such cases, the defendant argues that 'but for' the inducement by the government official, she would not have committed the crime. That is to say, the intention to commit the crime was caused by the deception rather than her pre-existing intentions. ${ }^{14}$ Similarly, but for the compensatory offer, the worker would not have subordinated her ends to those of her employer. In both cases, the incentive intervenes between the person's considered judgment (that is, avoid injury to others or to oneself) and the course of action that is actually chosen. Hence, while the accused or worker is responsible for her choice to inflict the harm on others or herself, she should not be held responsible for the burden of that choice (that is, punishment or work harm). What is important to note here is that the excusing force that is available to the worker is considerably stronger than that which is available to the offender. That is because, given the prospect of being compensated, there is no prior reason which might dissuade the worker from being induced (provided, of course, that the job itself does not involve some form of wrongdoing), whereas in the case of entrapment the duty to avoid harm to others provides the potential wrongdoer with a prior reason not be tempted by the official's enticement. Thus, while detrimental reliance absolves the promisee of responsibility, entrapment might only mitigate the offender's responsibility.

However, this account of causal responsibility is incomplete insofar as it does not adequately explain why the worker would be motivated to rely detrimentally 
on the employer's promise in the first place. Before enduring the work harm the worker requires sufficient assurance that the employer will fulfill his compensatory promise; for in the absence of such assurance the compensatory promise would hardly constitute an inducement. I would argue that the worker's demand for assurance is satisfied by her awareness of the employer's general duty to avoid the wrongful infliction of harm. More precisely, the employer is obliged to keep his promise because it would be wrong for him to create intentionally or negligently expectations that he has good reason to think will lead the worker to rely detrimentally on them. ${ }^{15}$ Hence, the worker is assured when she is aware that the employer knows he is obligated not to allow others to rely detrimentally on the expectations he has created. Notice that the employer's obligation is triggered simply by the fact that he has created an expectation, rather than because the expectation is actually relied upon. As a result, it evades the following form of circularity: the worker is motivated to rely detrimentally on the employer's promise when she is aware that the employer is obligated; but the employer is only obligated once the worker has detrimentally relied on the promise.

From the preceding discussion it should by now be clear that the purported force behind the employer's obligation to compensate stems from two sources: the fact of detrimental reliance and the prospect of detrimental reliance. In the first place, the employer's promise entails that he is causally responsible for the harm that has occurred. Because of that fact he is obligated to compensate in order to avoid the wrongdoing entailed by leaving the worker to suffer the consequences of relying on his promise. In the second place, the employer is obligated because of the duty to neutralize harm that he has good reason to believe will arise as a result of the expectations he has created. As we have seen, that duty of care serves to provide the employer with a reason for compensating that is prior and independent of actual detrimental reliance, as well as the assurance required in order to establish his causal responsibility for that reliance. ${ }^{16}$

A significant implication of this responsibility-based reading of promising is that the level of compensation that is due may depart from that which is mutually agreed by the employer and worker (namely, what is promised by the employer and accepted by the worker in advance of the harmful performance). That is, because the force behind the employer's obligation to compensate stems from his duty to avoid harmful reliance, what is required by that obligation need not coincide with what is required by the duty to keep one's word. If the worker retrospectively realizes that the harm incurred was more than the agreed compensatory wage was designed to make up for, the employer is obligated to rectify the shortfall. For it remains the case that, in the absence of the employer's compensatory promise, the unexpected loss would not have occurred. Equally, the employer is not required to fulfill the compensatory promise in its entirety if it turns out that the loss is less than foreseen. It is in such cases that the worker must appeal to the duty of fidelity to one's promises in order to ensure the full extent of the compensatory promise. ${ }^{17}$ 


\section{Three objections}

In order to unpack further the argument from detrimental reliance, I now turn to consider three challenges to it.

1. It may be objected that the line of reasoning presented here fails to establish the employer's causal responsibility for the worker's loss. For, or so the argument goes, in the absence of the worker's reciprocal promise to work, the employer's compensatory promise would not have been made in the first place. If that is right, then it appears we cannot pinpoint the employer's promise as the only necessary condition of the worker's loss. However, the problem of attributing cause does not arise when, as is the norm, workers are compensated retrospectively. For in that case, the employer does not require assurance that the worker will fulfill her reciprocal promise in order to motivate her own promise to compensate. All he requires is the foreknowledge that his obligation to compensate will be rendered void if the worker does not endure the harm. Thus, while the worker's reciprocal promise is useful in the sense that it would enable the employer to plan ahead, it is not a necessary precondition for him to make the compensatory promise. In the event that the worker is compensated in advance of her performance, I take it that the problem of grounding the worker's compensation claim simply does not arise. In that case, the tables are reversed insofar as it is the employer who must gather assurance from the worker's duty to avoid the wrongful infliction of harm, rather than from the fact that he will perform his promise last. Notice also that even the duty of care in the creation of expectations holds prior and independently of the worker's acceptance of the invitation to rely on the compensatory promise, whether that acceptance takes the form of promising to perform or actually performing the requested task. The employer becomes duty-bound in this way merely by inviting the worker to rely on the compensatory promise. In terms of causal responsibility and the duty of care, therefore, the presence of a counter-promise by the worker is superfluous.

2. Suppose that an employer promises a prospective employee a contributory wage in return for the expected value she will generate, but not a compensatory wage. Suppose also that, in spite of the uncompensated labor burdens the prospective employee will incur, the contributory wage would be sufficient to elevate her level of well-being above what it would be if she did not accept the job offer. In such cases, the argument from detrimental reliance does not render the employer duty-bound to make good the worker's loss simply because there was no promise to rely on. But it is exactly at this point that the argument from duress takes effect. That is to say, the worker is not responsible for her loss because she is acting out of necessity and the employer is obliged to compensate in order to prevent the exploitation of the worker's predicament (the assumption here is that a person with a reasonable alternative to turn to would not accept an uncompensated or under-compensated job offer). Charles Fried contends that in 
such cases the burden should be borne by society rather than the individual employer. In other words, resources should be redistributed (based in part on a tax on the profits of employers) such that citizens have a reasonable non-work alternative available to them. ${ }^{18}$ Thus, the onus lies with society to prevent duress, rather with the employer to avoid exploitation. The upshot of that line of argument would appear to be that society is obliged to compensate the worker when it has failed to provide an adequate social minimum.

3. Notice how the argument from detrimental reliance takes the same basic form as the argument from duress. In both cases, the circumstances in which the choice to work was made (the absence of an adequate non-work alternative or assurance that the employer will make good the deleterious effects of work) absolves the worker of responsibility for the resulting harm. It may be argued, however, that while a person's harmful choice is justified by the circumstances under which it is made, she remains responsible for the loss that results. Joel Feinberg, for example, argues that, while a person's decision to break into a cabin to escape a life-threatening blizzard constitutes a justified infringement, she is still obliged to pay the cabin's owner for the resulting damage to his property. ${ }^{19}$ The question is whether a person should incur the burden of his or her justified choice when, as is the case of voluntary labor burdens, that person is the victim. It is not obvious that there is a relevant difference between these two types of case. That is to say, it is not clear why a person should suffer the burden (providing compensation) of her justified choice when another person is the injured party (for example, the owner of the log cabin), while she should not suffer the burden (receiving compensation) of her justified choice when she herself is the injured party (for example, self-imposed labor burdens). If that is correct, then the worker and the blizzard survivor should either both incur the burden of their choice or both not incur the burden of their choice. Thus, if the blizzard survivor should bear the cost, then so should the worker. Feinberg appears to be inconsistent in this regard because he argues that the blizzard survivor should incur the burden while the worker should not (as we have seen in Section 3, he argues that the worker is due compensation as a way of expressing our sympathy toward her innocent loss).

The general view that I adhere to is that if we accept that a choice is justified by the circumstances in which it is made, then, because of that very fact, it would be unjustified to hold the chooser responsible for the burden of her choice. I would suggest that the inconsistency in Feinberg's position stems from the fact that he imbues rights with independent moral force. Once we accept that the rights of others have no or little moral bearing when mitigating circumstances pertain, there are no grounds for a compensation claim against the blizzard survivor. ${ }^{20}$ Hence, if we discard the idea that rights provide an independent basis for moral assessment, then choice due to the circumstances absolves the chooser of responsibility for the resulting burden, whether it is incurred by her or another. 
That is to say, the case of justified infringements (exampled here by the blizzard survivor) does not, due to the demands of consistency, commit us to the view that a worker should be left to suffer the consequences of her choice.

\section{Conclusion}

I began by noting how the pervasive influence of luck threatens to reduce the contributory wage to the role of directing workers to where they are most needed and to enticing them to work sufficiently hard once they are there. The central aim of this article has been to show that there is a compelling reason for providing the compensatory wage which, unlike its contributory counterpart, does not derive solely from efficiency. The basic challenge to that undertaking arose from the fact that the worker's loss was freely self-imposed and, therefore, that the compensatory wage only makes sense when interpreted as an incentive payment. My response has been to argue that the worker's acquiescence was subject to the assurance that the employer will make good the deleterious effects of work. Hence, the worker should not be held responsible for the labor burdens she endures even though she had the option of avoiding it. Insofar as that line of argument bears up to scrutiny, it remains the case that the compensatory determinant of the worker's wage possesses the authority that its contributory counterpart lacks.

\section{notes}

This article has benefited greatly from the comments of Thomas M. Besch, G.A. Cohen, Shlomi Segall, Lucas Thorpe, T.M. Wilkinson, Bill Wringe, Jonathan Wolff, and two anonymous referees.

1. The view that wage compensation is required in order to direct workers to where they are most needed and to entice them to work sufficiently hard once they are there is exampled in the economics literature by the theory of compensating (or equalizing) wage differentials. For the classic exposition of that theory, see Adam Smith, An Inquiry into the Nature and Causes of the Wealth of Nations (Chicago, IL: University of Chicago Press, 1977 [1776]), Book I, Chs 1-10, especially Ch. 10. Note, however, that the theory of compensating differentials is not strictly compensatory because the baseline to be restored by the compensation payment is defined by the welfare level made possible by the next best alternative job that is available to the worker. That baseline job may include payments in excess of the welfare loss that is brought about by performing it (that is, the worker's contributory wage).

2. In Strawsonian terms, by disregarding the attitudes and intentions that a person expresses toward ourselves or others we treat them as if they are incapable of participating in ordinary human relationships. See P.F. Strawson, 'Freedom and Resentment', in Free Will, edited by G. Watson (Oxford: Oxford University Press, 1982), pp. 66, 76. 
3. G.A. Cohen, 'The Pareto Arguments for Inequality', Social Philosophy and Policy 12 (1995): 170 fn. 34, 176 and G.A. Cohen, 'Incentives, Inequality and Community', in The Tanner Lectures On Human Values, Vol. 13, edited by G.B. Paterson (Salt Lake City: University of Utah, 1992), p. 296.

4. G.A. Cohen, 'On the Currency of Egalitarian Justice', Ethics 99 (1989): 916.

5. Legally speaking, the employer is obliged to make good the disappointment of the worker's 'expectations' rather than her 'reliance damages'. For an elucidation of this distinction, see P.S. Atiyah, Promises, Morals and Law (Oxford: Oxford University Press, 1981), pp. 16, 32-3.

6. On the link between moral motivation and gratitude, see Fred R. Berger, 'Gratitude', Ethics 85 (1975): 299-301.

7. Something approximating this is suggested by Sidgwick when he argues that good desert amounts to gratitude universalized. See H. Sidgwick, Method of Ethics, 7th edn (Indianapolis: Hackett Publishing, 1981 [1906]), Book III, Ch. V, Section 5, p. 279.

8. This represents a familiar basis for attempting to ground the claim to wage compensation. See, for example, Joel Feinberg, 'Justice and Personal Desert', in Doing and Deserving: Essays in the Theory of Responsibility (Princeton, NJ: Princeton University Press, 1970), especially the appendix 'Personal Income as Deserved'; James C. Dick, 'How to Justify a Distribution of Earnings', Philosophy and Public Affairs 2 (1975): 264-72; Wojciech Sadurski, Giving Desert its Due: Social Justice and Legal Theory (Dordrecht: D. Reidel, 1985), pp. 145-6; George Sher, Desert (Princeton, NJ: Princeton University Press, 1987), pp. 97-108; Julian Lamont, 'Incentive Income, Deserved Income and Economic Rents', Journal of Political Philosophy 5 (1997): 26-46.

9. The structural discordance between positive desert and compensation is well observed by David Miller, Social Justice (Oxford: Oxford University Press, 1976), pp. 111-13. For an insightful extension of that line of argument, see Serena Olsaretti, 'Distributive Justice and Compensatory Desert', in Desert and Justice, edited by S. Olsaretti (Oxford: Clarendon Press, 2003), pp. 187-204.

10. Feinberg, 'Justice and Personal Desert'.

11. Ibid., pp. 74-6, 92-4.

12. Feinberg's subsequent writings do not appear to provide us with a clear-cut way to handle the peculiarity of wage compensation, as, so long as the victim was provided with the right consenting conditions, he adheres to the volenti non fit injuria principle. He argues that trumping a person's autonomous choice (fully informed and voluntary, that is, competent, not coerced or subject to duress, not subject to manipulation, and not choosing because of ignorance or mistaken beliefs), even when it is deemed to be contrary to their own well-being, would be unacceptably paternalistic. See Joel Feinberg, Harm to Self: The Moral Limits of the Criminal Law (Oxford: Oxford University Press, 1986), pp. 57-61, 115-7 especially.

13. The argument that follows is similar to Judith Jarvis Thomson's brief analysis of compensation for losses that are voluntarily incurred. See Judith Jarvis Thomson, 'Rights and Compensation', Noûs 14 (1980): 10-13. The similarity becomes even clearer if we read that analysis in the light of her subsequent account of promissory obligation. See Judith Jarvis Thomson, 'Giving One's Word', in The Realm of Rights (Cambridge, MA: Harvard University Press, 1990), pp. 294-321. 
14. Here I follow what is called the subjective (that is, whether the accused was predisposed to commit the offence) rather than the objective (that is, whether an average person would have been induced to commit the offence) reading of the entrapment defense. On that distinction, see Gerald Dworkin, 'The Serpent Beguiled Me and I did Eat: Entrapment and the Creation of Crime', in The Theory and Practice of Autonomy (Cambridge: Cambridge University Press, 1988), Ch. 9, pp. 137-41. It seems to me that the distinction all but collapses when considered in the context of work harm. That is because, with the exception of the sadomasochistic and those who are morally motivated to sacrifice themselves, prospective workers would not freely (that is, without duress, force, a compulsive urge to harm themselves, and so on) self-impose work harm in the absence of a compensatory promise.

15. Here I draw from Neil MacCormick's influential discussion of promises. See Neil MacCormick, 'Voluntary Obligations and Normative Powers I', Proceedings of the Aristotelian Society, supplement, 46 (1972): 59-78.

16. In keeping with the idea of unjust enrichment, we may go a step further and argue that in the absence of promise fulfillment, the employer has no claim to the value associated with the worker's performance (irrespective of whether it is owned by the worker). That is, if the employer fails to compensate, her claim to the value created by the worker's performance is unfounded because it was acquired by wrongfully harming the worker. On the link between promise-keeping and wrongful gain, see Atiyah, Promises, Morals and Law, pp. 18-19, 40-41.

17. For such an account, see T.M. Scanlon's innovative discussion: T.M. Scanlon, What We Owe to Each Other (Cambridge, MA: Harvard University Press, 1998), Ch. 7, Section 3 and T.M. Scanlon, 'Promises and Contracts', in The Difficulty of Tolerance: Essays in Political Philosophy (Cambridge: Cambridge University Press, 2003), pp. 242-4. He argues that it is the duty to avoid denying the capacity for agency that stable expectations enable (the value of assurance, as he calls it), rather than simply what would be chosen based on those expectations, that grounds promissory obligation in general.

18. Charles Fried, Contract as Promise: A Theory of Contractual Obligation (Cambridge, MA: Harvard University Press, 1981), p. 106.

19. Joel Feinberg, 'Voluntary Euthanasia and the Inalienable Right to Life', Philosophy and Public Affairs 7 (1978): 101-2. That view may be defended on the grounds that the victim's loss would otherwise be left unrepaired. But even if the victim's predicament is acknowledged, it is not clear why it is the blizzard survivor, rather than society, that should make good the cabin owner's losses. See Peter Cane, Responsibility in Law and Morality (Oxford: Hart Publishing, 2002), pp. 106-8.

20. Compare with Thomson, 'Rights and Compensation' for a revealing analysis of justified infringements. 